13

\title{
Распыление поверхности кремния при низкоэнергетической высокодозовой имплантации ионами серебра
}

\author{
() В.В. Воробьев, ${ }^{1,2}$ А.М. Рогов, ${ }^{1,2}$ В.И. Нуждин, ${ }^{2}$ В.Ф. Валеев, ${ }^{2}$ А.Л. Степанов ${ }^{2}$ \\ ${ }^{1}$ Междисциплинарный центр „Аналитическая микроскопия“, КФУ, \\ 420008 Казань, Россия \\ ${ }^{2}$ Казанский физико-технический институт им. Е.К. Завойского ФИЦ КазНЦ РАН, \\ 420029 Казань, Россия \\ e-mail: Slavik.Ksu@mail.ru
}

Поступило в Редакцию 7 апреля 2019 г.

В окончательной редакции 3 февраля 2020 г.

Принято к публикации 10 февраля 2020 г.

\begin{abstract}
Приведены результаты по впервые проведенным на практике наблюдениям распыления поверхности $\mathrm{Si}$ при имплантации ионами $\mathrm{Ag}^{+}$с энергией $30 \mathrm{keV}$ в зависимости от дозы облучения $D$ в интервале от $2.5 \cdot 10^{16}$ до $1.5 \cdot 10^{17} \mathrm{ion} / \mathrm{cm}^{2}$ при фиксированном значении плотности тока в ионном пучке $J=8 \mu \mathrm{A} / \mathrm{cm}^{2}$, а также при вариации $J=2,5,8,15$ и $20 \mu \mathrm{A} / \mathrm{cm}^{2}$ для постоянной величины $D=1.5 \cdot 10^{17} \mathrm{ion} / \mathrm{cm}^{2}$. В первом случае наблюдается монотонное увеличение толщины распыляемого слоя пористого $\mathrm{Si}$ (PSi) до $50 \mathrm{~nm}$ при максимальной $D$, при этом значение эффективного коэффициента распыления имплантированного слоя $\mathrm{Ag}$ : PSi составляет 1.6. Также установлено возрастание толщины распыленного слоя при повышении $J$.
\end{abstract}

Ключевые слова: распыление кремния, низкоэнергетическая ионная имплантация, ионы серебра.

DOI: 10.21883/JTF.2020.07.49457.153-19

\section{Введение}

В настоящее время на практике для преобразования солнечной энергии в электрическую используются коммерческие элементы, состоящие из достаточно толстых пластин кристаллического кремния $(c-\mathrm{Si})$ от 180 до $300 \mathrm{mkm}$ [1]. Основные расходы на изготовление солнечных батарей определяются затратами на выращивание и последующую технологическую обработку таких толстослойных подложек $c$-Si. Поэтому актуальным и экономически важным является создание солнечных элементов на тонких слоях $\mathrm{Si}(<1 \mu \mathrm{m})$ с аморфной или поликристаллической структурой [2,3]. Тонкослойные солнечные элементы малой массы могут быть интегрированы с современными компактными оптоэлектронными микросхемами и устройствами на основе $\mathrm{Si}$, а следовательно, найти применение в авиационной и космической промышленности.

Основным ограничением для эффективного использования тонкопленочных солнечных элементов является достаточно низкое поглощение в видимой области света вблизи края фундаментальной полосы непрямозонного полупроводника - $\mathrm{Si}$. C целью повышения поглощательной способности солнечных элементов на основе $\mathrm{Si}$ относительно недавно был предложен подход, заключающийся во включении в структуру тонких слоев $\mathrm{Si}$ наночастиц благородных металлов малых размеров $(<30 \mathrm{~nm})[4,5]$, в которых под действием света возникает локализованный поверхностный плазмонный резонанс. Такой резонанс наночастиц проявляется в интенсивном поглощении света металлическими наночастицами в области ультрафиолетового, видимого и ближнего инфракрасного спектральных диапазонах [6,7], что и обеспечивает суммарный вклад в повышенное поглощение тонкого полупроводникового слоя, содержащего наночастицы [8]. Более того, возникающее вблизи наночастиц вследствие плазмонного резонанса локальное электромагнитное поле способно генерировать появление электронно-дырочных пар в полупроводниках [5]. При этом на практике наночастицы из $\mathrm{Ag}$ рассматриваются для солнечных элементов на основе $\mathrm{Si}$ как наиболее перспективные по степени эффективности плазмонного возбуждения и селективного поглощения в видимом диапазоне света [9].

Для формирования композиционных $\mathrm{Si}-$ слоев с наночастицами Ag используются различные методы: атмосферное лазерное осаждение [10], вакуумное осаждение металла [11], различные химические подходы [12] и т.д. Особый интерес вызывает технология ионной имплантации, которая активно используется в промышленной $\mathrm{Si}-$ микроэлектронике. Имплантация $c$-Si такими ионами, как $\mathrm{B}^{+}$и $\mathrm{P}^{+}$, изменяет тип проводимости $\mathrm{Si}$, улучшает его фотовольтаические свойства, что находит свое применение при разработке элементов солнечных батарей $[13,14]$. Однако исследований по синтезу наночастиц благородных металлов в матрице $\mathrm{Si}$ при ионной имплантации для приложений в солнечной энергетике ранее на практике не проводилось.

Недавно нами была предложена новая технология формирования тонких пористых слоев $\mathrm{Si}$ с наночастицами $\mathrm{Ag}(\mathrm{Ag}: \mathrm{PSi})$ при низкоэнергетической высокодозовой $\left(>10^{16} \mathrm{ion} / \mathrm{cm}^{2}\right)$ имплантации $c$-Si ионами $\mathrm{Ag}^{+}$ $(\mathrm{Ag}: \mathrm{Si})[15,16]$. В этих работах было показано, что при имплантации $c-\mathrm{Si}$ ионами $\mathrm{Ag}^{+}$с низкой энергией 
$E=30 \mathrm{keV}$ и высокой дозой $D=1.5 \cdot 10^{17} \mathrm{ion} / \mathrm{cm}^{2}$, одновременно с синтезом наночастиц $\mathrm{Ag}$ и формированием пористой структуры PSi происходит эффективное распыление поверхности полупроводника. Несмотря на то что в научной литературе вопросам распыления $\mathrm{Si}$ при ионной имплантации уделено достаточно много внимания (см. например, обзоры $[17,18])$, информация о характере распыления $\mathrm{Si}$, связанная конкретно с тяжелым ионом $\mathrm{Ag}^{+}$, в литературе отсутствует. Поэтому в настоящей работе впервые проведены количественные эксперименты по ионному низкоэнергетическому распылению $\mathrm{Si}$ в зависимости от плотности тока в ионном пучке $J$ и дозы облучения $D$ при имплантации ионами $\mathrm{Ag}^{+}$.

\section{Методика эксперимента}

В качестве подложек для ионной имплантации использовались монокристаллические пластины $c$-Si с кристаллографической ориентацией (100). Имплантация проводилась ионами $\mathrm{Ag}^{+}$с $E=30 \mathrm{keV}$ для различных значений дозы $D$ в интервале от $1.5 \cdot 10^{15}$ до $1.5 \cdot 10^{17} \mathrm{ion} / \mathrm{cm}^{2}$ при постоянной величине плотности тока $J=8 \mu \mathrm{A} / \mathrm{cm}^{2}$, а также для фиксированной $D=1.5 \cdot 10^{17} \mathrm{ion} / \mathrm{cm}^{2}$ при $J=2,5,8,15$ и $20 \mu \mathrm{A} / \mathrm{cm}^{2}$. Имплантация выполнялась на ионном ускорителе ИЛУ-3 при комнатной температуре облучаемой подложки и нормальном падении пучка ионов на облучаемую поверхность $c$-Si. C целью изучения процесса распыления $\mathrm{Si}$ ионами $\mathrm{Ag}^{+}$, а также определения эффективного коэффициента распыления $k$ имплантированного пористого слоя $\mathrm{Ag}$ : $\mathrm{PSi}$, на поверхности $\mathrm{Si}$ формировалась граница между облученным и необлученным участками образца (ступенька). Для этого ионная имплантация $c$-Si осуществлялась через медноникелевую маску - сетку с размером ячеек $90 \mu \mathrm{m}$ при периоде $125 \mu \mathrm{m}$, помещаемую на поверхность образца во время облучения. Экспериментальные данные по распылению для каждой исследуемой $D$ и $J$ получены по измерениям на 5 образцах.

Морфология поверхности образцов исследовалась на сканирующем электронном микроскопе (СЭМ) Merlin (Carl Zeiss) с использованием внутрилинзового детектора вторичных электронов In-Lens. При тех же параметрах электронного микроскопа, но при наклоне образца относительно направления зондирующего луча на угол, равный $70^{\circ}$, выполнялись структурные измерения методом дифракции отраженных электронов (ДОЭ) с помощью детектора NordLys HKL (Oxford Instruments). Регистрация изображений поперечного скола образцов проводилась на СЭМ Hitachi SU 8230 в режиме детектирования вторичных электронов. Для этого образец помещался на предметный столик под наклоном $70^{\circ}$ относительно направления падающего пучка электронов. Элементный анализ был выполнен с помощью энергодисперсионного (ЭДС) спектрометра X-Max (Oxford Instruments), комбинированного с тем же микроскопом.
Для наблюдения детальной топологии поверхности образцов был использован сканирующий зондовый микроскоп (С3M) Dimension FastScan (Bruker). Измерения проводились в режиме количественного наномеханического картирования зондами с жесткостью $0.4 \mathrm{~N} / \mathrm{m}$ и радиусом закругления $\sim 5 \mathrm{~nm}$. Оптические изображения имплантированных образцов также были получены с помощью оптического микроскопа Микромед ПОЛАР 1.

\section{Результаты и обсуждение}

Как ранее обсуждалось в работах $[19,20]$, из данных по оптической эллипсометрии и ДОЭ следует, что приповерхностный слой $\mathrm{Si}$, сформированный имплантацией ионами $\mathrm{Ag}^{+}$, оказывается полностью аморфизированным уже при достижении малой $D \sim 1.3 \cdot 10^{14} \mathrm{ion} / \mathrm{cm}^{2}$. В качестве примера на рис. 1 приведены ДОЭ-изображения для неимплантированного $c$ - $\mathrm{Si}$, а также облученного при $D \sim 1.3 \cdot 10^{14} \mathrm{ion} / \mathrm{cm}^{2}$ и $J=8 \mu \mathrm{A} / \mathrm{cm}^{2}$. Из рисунка видно, что в отличие от исходного образца, ДОЭ которого характеризуется картиной с линиями Кикучи монокристалла $c-\mathrm{Si}$, на ДОЭ-изображении для $\mathrm{Ag}: \mathrm{Si}$ образца проявляются только диффузные кольца, свидетельствующие об аморфизации приповерхностного имплантированного слоя. Появление аморфной структуры также было подтверждено спектрами оптического отражения, приведенными в работе [21], в которой для характерных полос отражения $c$-Si было обнаружено снижение интенсивности при максимуме $268 \mathrm{~nm}$ до $75 \%$ и полное пропадание полосы при $366 \mathrm{~nm}$, инициированное появлением аморфного слоя $a$-Si и образованием пористой поверхности PSi при имплантации с $D=1.5 \cdot 10^{17} \mathrm{ion} / \mathrm{cm}^{2}$.

В начальный момент имплантации после разрушения кристаллической структуры и аморфизации имплантированного слоя начинает меняться морфология поверхности облучаемого $\mathrm{Si}$, приводящая к появлению пор $[15,20]$. В качестве примера на рис. 2 приведено СЭМ-изображение поперечного скола для образца $\mathrm{Ag}: \mathrm{PSi}$, сформированного при $D=1.5 \cdot 10^{17} \mathrm{ion} / \mathrm{cm}^{2}$ и $J=8 \mu \mathrm{A} / \mathrm{cm}^{2}$. Темная область на нижней половине СЭМ-изображения образца (рис. 2) соответствует торцевой стороне подложки исходного $c$-Si. На верхней части рисунка показана поверхность под углом. На данной поверхности наблюдается открытые поры $\mathrm{Si}$. При этом по периметру стенок пор расположены крупные наночастицы $\mathrm{Ag} \sim 40 \mathrm{~nm}$, а мелкие наночастицы $(\sim 7 \mathrm{~nm})$ распределены равномерно по всей площади образца.

Как было указано во введении, при имплантации ионами $\mathrm{Ag}^{+}$в $c$-Si при достаточно высоком значении $D=1.5 \cdot 10^{17} \mathrm{ion} / \mathrm{cm}^{2}$ было зафиксировано распыление поверхности полупроводника $[15,16]$. С тем чтобы определить зависимость изменения толщины $(h)$ распыленного слоя от длительности ионного облучения $(D)$, была проведена серия экспериментов с облучением через поверхностную маску $c$-Si ионами $\mathrm{Ag}^{+}$, начиная с малой дозы $\left(D=1.5 \cdot 10^{15} \mathrm{ion} / \mathrm{cm}^{2}\right)$. 

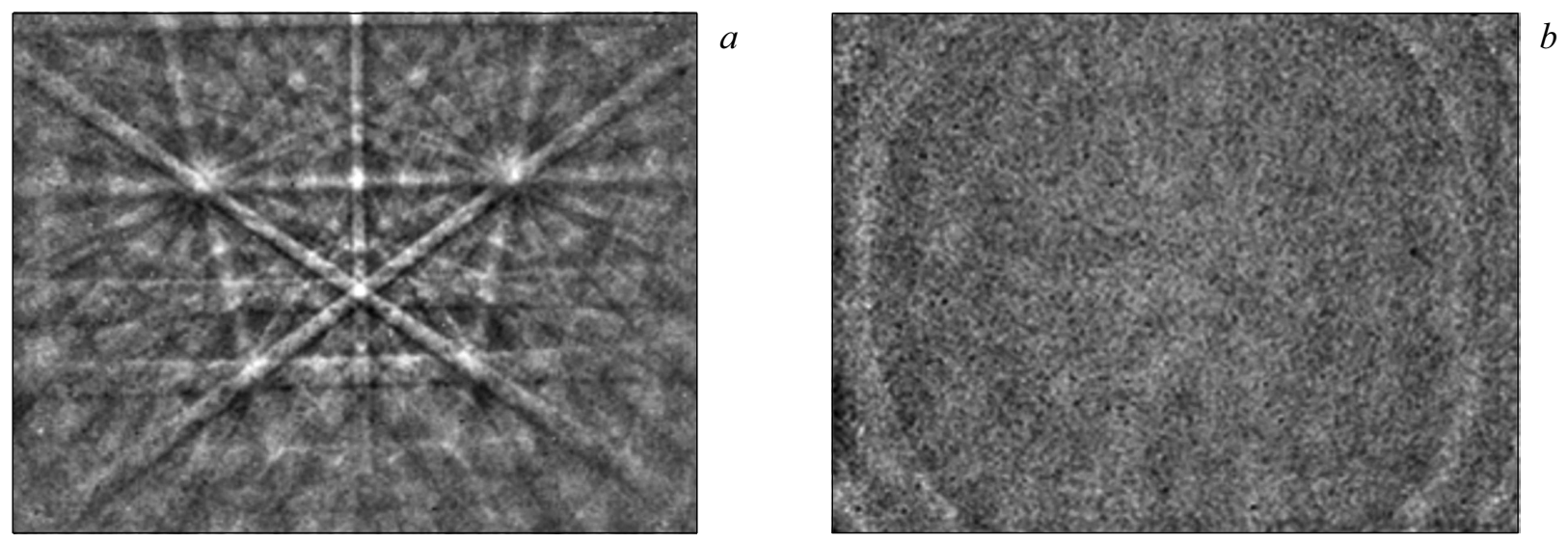

Рис. 1. ДОЭ-картины для исходного $c-\mathrm{Si}(a)$ и $\mathrm{Si}$, имплантированного ионами $\mathrm{Ag}^{+}$при $D=1.3 \cdot 10^{14}$ ion $/ \mathrm{cm}^{2}$ и $J=8 \mu \mathrm{A} / \mathrm{cm}^{2}(b)$.

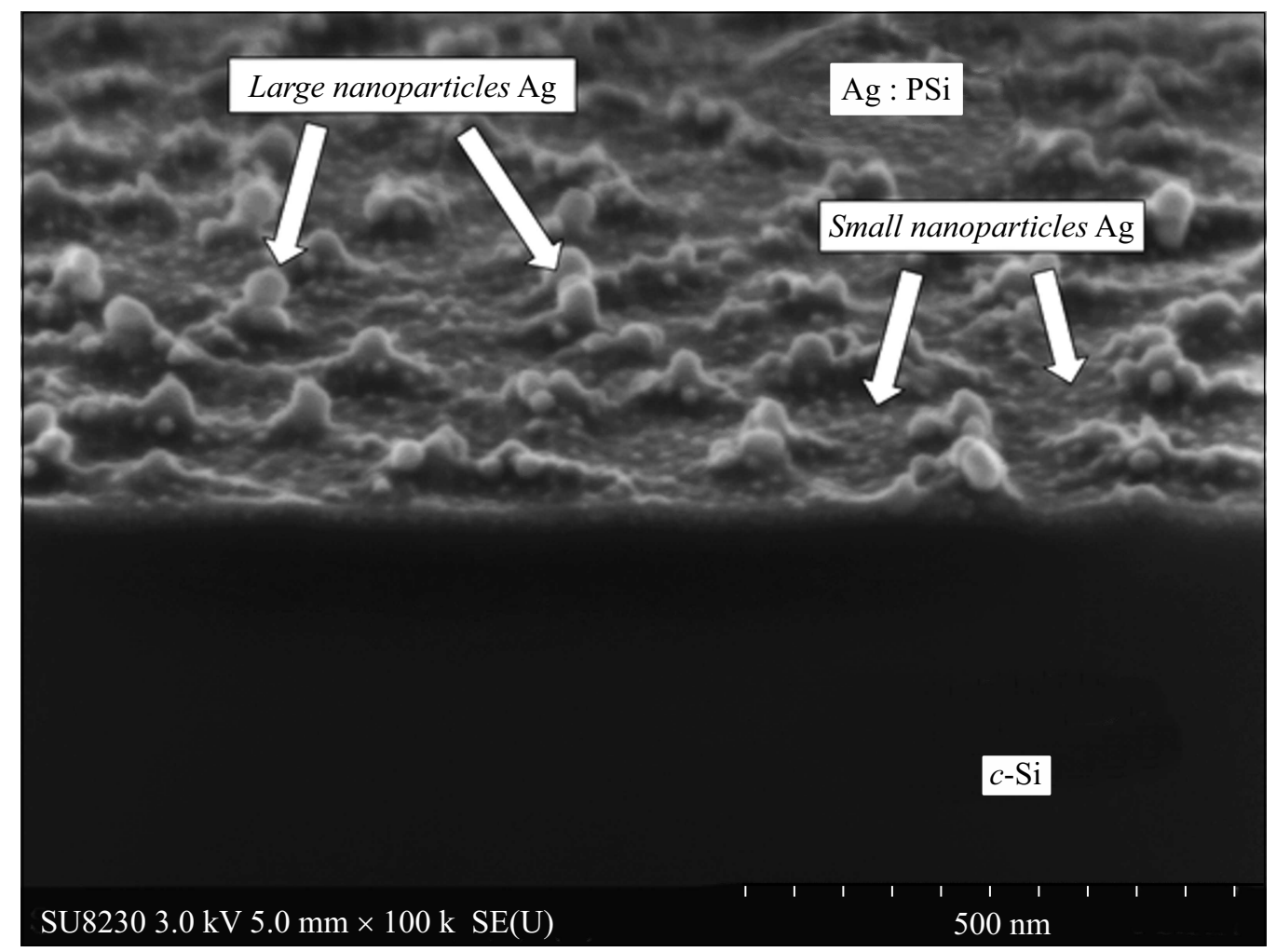

Рис. 2. СЭМ-изображение поперечного скола $\mathrm{Ag}$ : Рsi, имплантированного ионами $\mathrm{Ag}^{+}$при $D=1.5 \cdot 10^{17}$ ion $/ \mathrm{cm}^{2}$ и $J=8 \mu \mathrm{A} / \mathrm{cm}^{2}$.

На рис. 3, а приведен пример изображения, полученного на оптическом микроскопе при наблюдении на отражение, поверхности Ag: PSi образца, подвергнутого имплантации через маску ионами $\mathrm{Ag}^{+}$при максимальном используемом значении $D=1.5 \cdot 10^{17} \mathrm{ion} / \mathrm{cm}^{2}$ и $J=8 \mu \mathrm{A} / \mathrm{cm}^{2}$. На приведенном рисунке видно наличие на поверхности образца периодической структуры с отдельными квадратными ячейками (светлые области), совпадающими по геометрическим размерам с наложенной маской-сеткой (темные области). Подтверждением образования поверхностной периодической структуры в результате имплантации $c-\mathrm{Si}$ ионами $\mathrm{Ag}^{+}$через маску также служит изображение того же образца, полученное на СЭМ (рис. 3, b).

С целью наблюдения более детальной картины на границе сформированной имплантацией периодической структуры по поверхности образцов и проведения количественных оценок формируемых профилей были проведены измерения на СЗМ. На СЗМ-изображениях (рис. 4) приведен фрагмент периодической структуры образца, полученного при $D=1.5 \cdot 10^{17} \mathrm{ion} / \mathrm{cm}^{2}$ и $J=8 \mu \mathrm{A} / \mathrm{cm}^{2}$. На трехмерном СЗМ-изображении (рис. 4, $a$ ) отчетливо видно, что неимплантированная поверхность $c$-Si в виде стенки решетки (находящаяся под маской во вре- 

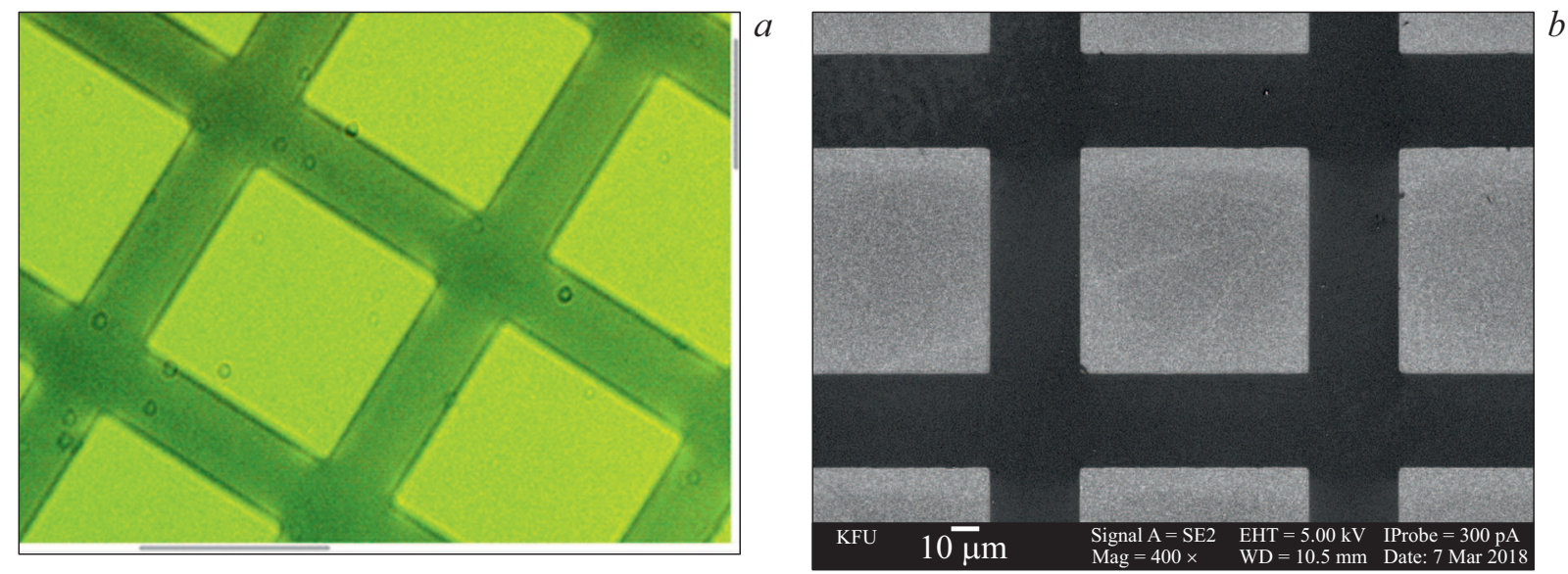

Рис. 3. Изображения, полученные на оптическом микроскопе $(a)$ и СЭМ $(b)$ поверхности $\mathrm{Si}$, имплантированного через маску ионами $\mathrm{Ag}^{+}$при $D=1.5 \cdot 10^{17} \mathrm{ion} / \mathrm{cm}^{2}$ и $J=8 \mu \mathrm{A} / \mathrm{cm}^{2}$.

$a$

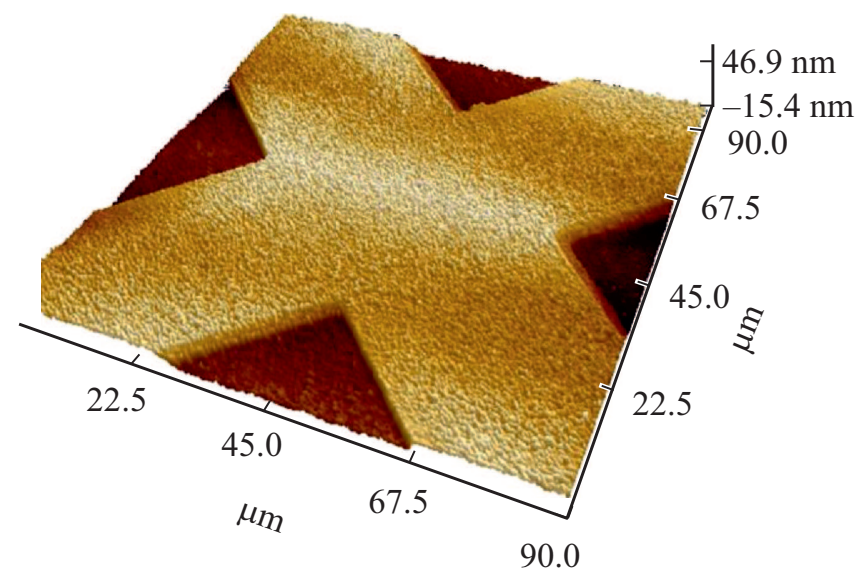

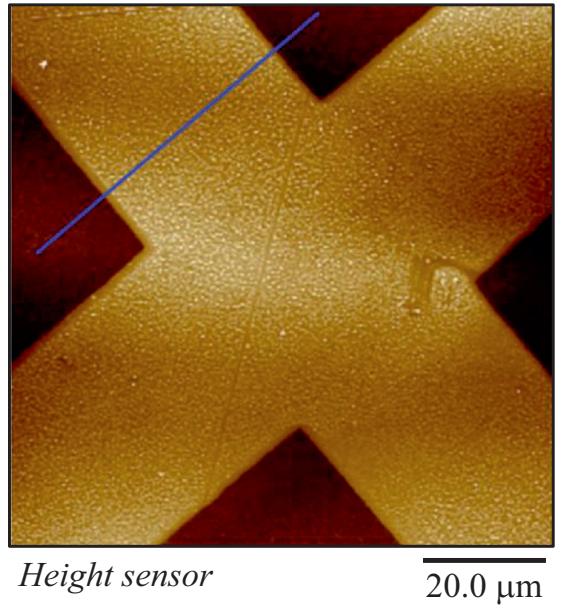

$c$

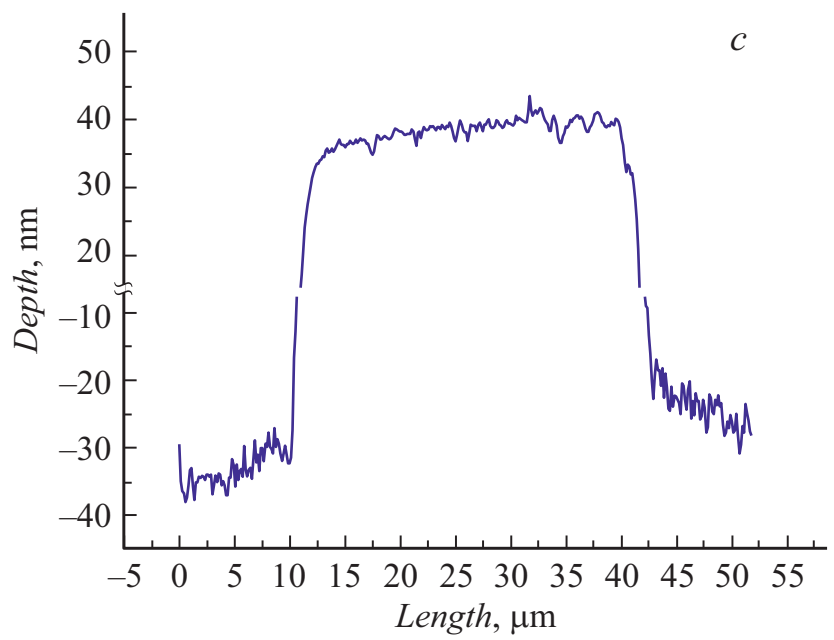

$b$

$\square^{68.6}$ 


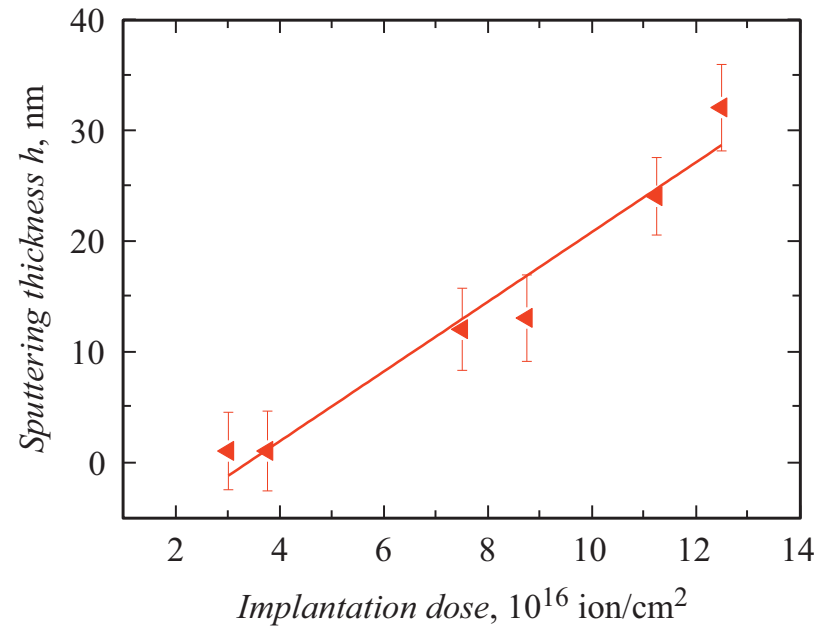

Рис. 5. График зависимости $h$ для образцов $\mathrm{Ag}$ : $\mathrm{PSi}$, сформированных при различных значениях $D$ и фиксированной величине $J=8 \mu \mathrm{A} / \mathrm{cm}^{2}$.

мя облучения) возвышается над ионно-распыленными ячейками решетки. Также, исходя из цветовой шкалы, приведенной справа от изображения участка (рис. $4, b$ ), можно заключить, что более светлые участки, соответствующие неимплантированной (защищенный маской) области образца, возвышаются над имплантированными квадратными фрагментами поверхности, проявляющиеся темным оттенком. Как было отмечено, крупное по масштабу изображение позволяет провести количественные замеры и получить оценки размерных параметров сформированных ячеек. В качестве примера для данного образца определен профиль (рис. 4, c), измеренный поперек стенки ячейки, как это показано линией на рис. 4, $b$. Из полученного профиля установлено, что $h=60 \mathrm{~nm}$.

В ходе проведенных экспериментов по ионной имплантации через маску для различных $D$ и постоянном значении $J=8 \mu \mathrm{A} / \mathrm{cm}^{2}$ регистрировать на СЗМ появление ступеньки (распыления) при разумных погрешностях измерения удается для образцов $\mathrm{Ag}: \mathrm{Si}$, сформированных при $D \geq 2.5 \cdot 10^{16} \mathrm{ion} / \mathrm{cm}^{2}$. Поэтому для образцов, полученных в интервале $D$ от $2.5 \cdot 10^{16}$ до $1.5 \cdot 10^{17} \mathrm{ion} / \mathrm{cm}^{2}$ и были проведены измерения профилей поверхности и определены значения $h$. Как результат, на рис. 5 приведена зависимость $h(D)$ для имплантированной ионами $\mathrm{Ag}^{+}$поверхности $\mathrm{Ag}: \mathrm{Si}$, из которой следует, что величина $h$ монотонно и линейно увеличивается с ростом $D$.

Как следует из представленных данных, при имплантации ионами $\mathrm{Ag}^{+} c$-Si c ростом $D$ поверхность образца аморфизируется (рис. 1) и перестает быть ровной и гладкой (рис. 2), а также насыщается ионами $\mathrm{Ag}^{+}$, которые приводят к образованию наночастиц Ag. Поэтому говорить о коэффициенте распыления $k$ для чистого $\mathrm{Si}$ неправомерно. Однако экспериментально установленные значения $\mathrm{h}$ позволяют определить значения эффективного коэффициента распыления $k_{\mathrm{eff}}(D)$, характеризующего образцы $\mathrm{Ag}: \mathrm{Si}$, сформированные на различных этапах ионной имплантации. Из полученного линейного экспериментального профиля (рис. 5) следует, что $k_{\mathrm{eff}}(D)$ оказывается постоянной величиной. По определению

$$
k_{\mathrm{eff}}(D)=\Delta n_{\mathrm{Si}} / \Delta n_{\mathrm{Ag}},
$$

где $\Delta n_{\mathrm{Si}}$ - количество выбитых атомов из облучаемого материала, а $\Delta n_{\mathrm{Ag}}-$ количество имплантированных ионов $\mathrm{Ag}^{+}$, участвующих в ионном распылении. Для конкретной $D$

$$
\Delta n_{\mathrm{Si}}=\frac{\rho S \Delta h N_{A}}{M},
$$

где $\rho$ - плотность $\mathrm{Si}, S$ и $\Delta h$ площадь и высота распыленного имплантацией слоя, $N_{A}-$ постоянная Авогадро, $M$ - молярная масса $\mathrm{Si}$. Таким образом, оцененная величина составляет $k_{\mathrm{eff}}(D)=1.6$.

Отдельного внимания заслуживают измерения, проведенные по подобной методике для образцов, сформированных при постоянном значении $D=1.5 \cdot 10^{17} \mathrm{ion} / \mathrm{cm}^{2}$, но для различных значений $J$. На рис. 6 приведены экспериментальные данные зависимости $h(J)$ и $k_{\mathrm{eff}}(J)$. Очевидно, что $k_{\text {eff }}(J)$ будет менять свою величину при изменении $J$ во время имплантации $c$-Si ионами $\mathrm{Ag}^{+}$.

Согласно научной литературе [22], в зависимости от механизма протекания процесса различают столкновительное распыление (называемое также физическим или ионным), распыление вследствие электронных процессов (электронное распыление) и химическое распыление. В рассматриваемом случае при имплантации столкновительное распыление связано с передачей кинетической энергии от ускоренного иона $\left(\mathrm{Ag}^{+}\right)$атомам облучаемой матрицы $(\mathrm{Si})$, оно является доминирующим в той области энергий бомбардирующих ионов, где преобладают упругие удельные потери энергии падающих ионов (ядерные торможения). Вследствие этого некоторые атомы приобретают энергию, превышающую их энергию связи с поверхностью, и покидают мишень. При имплантации $\mathrm{Si}$ ионами $\mathrm{Ag}^{+}$с энергией $30 \mathrm{keV}$ как раз и

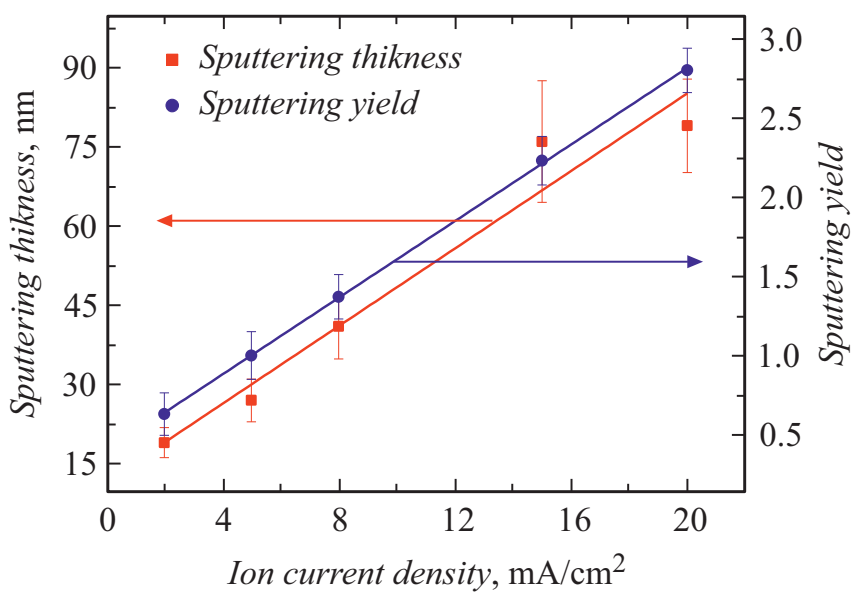

Рис. 6. График зависимости $h$ для образцов $\mathrm{Ag}: \mathrm{PSi}$, сформированных при различных значениях $J$ и фиксированной величине $D=1.5 \cdot 10^{17} \mathrm{ion} / \mathrm{cm}^{2}$. 
доминируют ядерные торможения, поэтому распылением вследствие электронных процессов, обусловленных энергией, затрачиваемой электронами на возбуждение и ионизацию атомов $\mathrm{Si}$, можно пренебречь. Также нет необходимости рассматривать химическое распыление, обусловленное химическими реакциями падающих ионов $\mathrm{Ag}^{+}$и атомов $\mathrm{Si}$ (за отсутствием таковых) с образованием на поверхности образца летучих соединений.

Теории столкновительного распыления основаны на рассмотрении каскадов упругих столкновений в облучаемых матрицах, при этом различают три режима [22]. Первый - это режим прямого выбивания атомов мишени, который возникает при имплантации мишеней легкими ионами. Протяженность каскадов невелика, и значительный вклад в распыление дают первично выбитые атомы. Второй механизм называют режимом линейных каскадов, и он реализуется для большинства ионов (кроме самых тяжелых) с энергиями от единиц до десятков килоэлектронвольт, что согласуется с применяемой энергией $30 \mathrm{keV}$. Плотность распределения атомов мишени, выбитых из своих равновесных положений, невелика, так что преобладают столкновения движущихся атомов с неподвижными атомами облучаемой матрицы, тогда как столкновения движущихся атомов между собой не происходит. Третьим режимом является режим нелинейных каскадов (тепловых пиков - локального разогрева облучаемого материала при передаче энергии от падающего иона к атомам мишени). Он характерен для ионов с большой массой. При этом плотность распределения атомов отдачи в матрице настолько высока, что большинство атомов внутри некоторого объема (объема теплового пика) находятся в движении.

Очевидно, что для достаточно тяжелых ионов $\mathrm{Ag}^{+}$, рассматриваемых в настоящей работе, первый режим распыления исключается, и наблюдаемые процессы должны характеризоваться каскадными теориями. При этом достаточно сложно отдать предпочтение линейным и нелинейным режимам каскадов.

\section{Заключение}

Таким образом, представлены результаты впервые проведенных экспериментов по распылению имплантированного поверхностного слоя $\mathrm{Si}$ при его низкоэнергетическом облучении ионами $\mathrm{Ag}^{+}$. Для этого была отработана прецизионная технология ионной имплантации через маску, а также выработана методика количественных СЗМ-измерений и оценок полученных структур. Установлено, что с ростом ионной $D$ поверхность $\mathrm{Si}$ аморфизируется и приобретает пористую структуру, а также в ней образуются наночастицы серебра. Экспериментально определены зависимости $h(D)$ и $h(J)$. Показано, что распыление неоднородных по структуре и химическому составу имплантированных слоев на основе $\mathrm{Si}$ можно характеризовать эффективным коэффициентом распыления $k_{\text {eff. }}$

\section{Благодарности}

Ионная имплантация была проведена в Казанский физико-технический институт им. Е.К. Завойского обособленное структурное подразделение ФИЦ КазНЦ РАН. Морфологический анализ полученных образцов был проведен на базе приборов Междисциплинарного центра „Аналитическая микроскопия“ Казанского федерального университета.

\section{Финансирование работы}

Работа выполнена при поддержке гранта РНФ № 17-12-01176.

\section{Конфликт интересов}

Авторы заявляют, что у них нет конфликта интересов.

\section{Список литературы}

[1] Миличко В.А., Шалин А.С., Мухин И.С., Ковров А.Э., Красилин А.А., Виноградов А.В., Белов П.А., Симовский К.Р. // УФН. 2016. Т. 186. С. $801-852$.

[2] Чопра К., Дас С. Тонкопленочные солнечные элементы. М.: Мир, 1986. 435 с.

[3] Polman A., Knight M., Garnett E.C., Ehrler B., Sinke W.C. / Science. 2016. Vol. 352. P. add4424-1-add4424-10.

[4] Polman A. // Science. 2008. Vol. 322. P. 868-869.

[5] Atwater H.A., Polman A. // Natur Mater. 2010. Vol. 9. P. 205-213.

[6] Kreibig U., Volmer M. Optical properties of metal clusters. Berlin: Springer, 1995. 533 p.

[7] Stepanov A.L. Ion implantation synthesis and optics of metal nanoparticles. Lambert Acad. Publ:: Mauritius, 2018. 426 c.

[8] Rockstuhl C., Fahr S., Lederer F. // J. Appl. Phys. 2008. Vol. 104. P. 123102-1-123102-123107.

[9] Sardana S.K., Chava V.S.N., Komarala V.K. // Appl. Surf. Sci. 2015. Vol. 347. P. 651-656.

[10] Козадаев К.В., Леончик С.В., Новиков А.Г., Зинчук О.В., Баран Л.В. // ЖПС. 2016. Т. 83. № 5. С. 736-741.

[11] Chervinskii S., Matikainen A., Dergachev A., Lipovskii A., Honkanen S. // Nanoscale Res. Lett. 2014. Vol. 9. P. 398-405.

[12] Yurova N.S., Markina N.E., Pozharov M.V., Zakharevich A.M., Rusanova T.Yu., Markin A.V. // Collois Surf. A: Physicochem. Eng. Aspects. 2016. N 495. P. $169-175$.

[13] Lee C.M., Chang S.-P., Chang S.-J., Wu C.-I. // Int. J. Electrochem. Sci. 2013. Vol. 8. P. 7634-7645.

[14] Баталов Р.И., Нужоин В.И., Валеев В.Ф., Нургазизов Н.И., Бухараев А.А., Ивлев Г.Д., Степанов А.Л. // Опт. и спектр. 2019. Т. 126. Вып. 2. С. 214-219.

[15] Stepanov A.L., TrifonovA.A., Osin Y.N., Valeev V.F., Nuzhdin V.I. // Optoelectron. Adv. Mat. Rapid Comm. 2013. Vol. 7. P. 692-697.

[16] Stepanov A.L., Nuzhdin V.I., Valeev V.F., Vorobev V.V., Rogov A.M., Osin Y.N. // Vacuum. 2019. Vol. 7. P. 353-357.

[17] Nastasi M., Mayer J.W., Hirvonen J.K. Ion-solid interactions. Fundamentals and applications. Cambridge: Cambridge Univ. Press, 1996. 540 p. 
[18] Распыление твердых тел ионной бомбардировкой / Под ред. Р. Бериш. М.: Мир, 1984. 336 с.

[19] Базаров В.В., Нужсин В.И., Валеев В.Ф., Воробьев В.В., Осин Ю.Н., Степанов А.Л. // ЖПС. 2016. Т. 83. № 1. C. $55-59$.

[20] Воробьев В.В., Рогов А.М., Осин Ю.Н., Нуждин В.И., Валеев В.Ф., Эйдельман К.Б., Табачкова Н.Ю., Ермаков М.А., Степанов А.Л. // ЖТФ. 2019. Т. 89. Вып. 2. C. $226-234$.

[21] Stepanov A.L., Osin Y.N., Vorobev V.V., Valeev V.F., Nuzhdin V.I. // Optoelectron. Adv. Mat. Rapid Comm. 2017. Vol. 11. P. 685-690.

[22] Фундаментальные и прикладные аспекты распыления твердых тел. / Под. ред. Е.С. Машкова. М.: Мир, 1989. $349 \mathrm{c}$. 